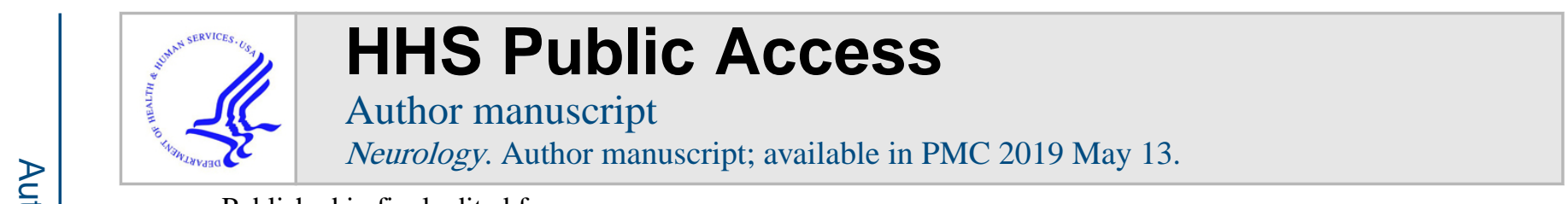

Published in final edited form as:

Neurology. 2017 August 08; 89(6): 641. doi:10.1212/WNL.0000000000004205.

\title{
LETTER RE: PREVALENCE AND INCIDENCE OF EPILEPSY: A SYSTEMATIC REVIEW AND META-ANALYSIS OF INTERNATIONAL STUDIES
}

\author{
Matthew Zack and Rosemarie Kobau \\ Atlanta, Georgia
}

\begin{abstract}
Noting variability around epilepsy burden estimates, Fiest et al. ${ }^{1}$ aimed to provide "a comprehensive synthesis of the prevalence and incidence of epilepsy from published international studies." 1 This article, which may be widely cited, is problematic.
\end{abstract}

The authors omitted at least 2 references that meet the study's search criteria (appendix e-1) ${ }^{1}$ but not its exclusionary criteria (figure 1). ${ }^{1-3}$ The authors noted the possibility of missing other studies (i.e., from Australia), but did not adequately account for this discrepancy relative to efforts around conducting a comprehensive synthesis.

Despite some acknowledgement of the heterogeneity of the estimates of active period prevalence (figure 2) and incidence (figure 3, A and B), based on $I^{2}$ statistics close to $100 \%$ and statistically significant $Q$ statistics, the authors still reported pooled estimates. ${ }^{1}$ These latter estimates misrepresent the extreme heterogeneity evident in the figures. At minimum, the authors should more clearly indicate and discuss the unreliability of these pooled estimates to alert readers about the possible misuse. Readers might consider citing the range of all or country-specific estimates when referencing study outcomes.

Further, the authors miscited reference 167 (appendix e-3) used in figure 2, ${ }^{1,4}$ which should instead be referenced as the Centers for Disease Control and Prevention. ${ }^{5}$

\section{References}

1. Fiest KM, Sauro KM, Wiebe S, et al. Prevalence and incidence of epilepsy: a systematic review and meta-analysis of international studies. Neurology 2017;88:296-303. [PubMed: 27986877]

2. Centers for Disease Control and Prevention (CDC). Epilepsy in adults and access to care: United States, 2010. MMWR Morb Mortal Wkly Rep 2012;61:909-913. [PubMed: 23151949]

3. Holden EW, Thanh Nguyen H, Grossman E, et al. Estimating prevalence, incidence, and diseaserelated mortality for patients with epilepsy in managed care organizations. Epilepsia 2005;46:311319. [PubMed: 15679513]

4. Centers for Disease Control and Prevention (CDC). Detection of notifiable diseases through surveillance for imported plague: New York, September-October 1994. MMWR Morb Mortal Wkly Rep 1994;43:805-807. [PubMed: 7968995]

5. Centers for Disease Control and Prevention. Current trends prevalence of self-reported epilepsy: United States, 1986-1990. MMWRMorb Mortal Wkly Rep 1994;43:810-811, 817-818. 